\title{
O Tema 793 do STF e o direcionamento do cumprimento das prestações na área de saúde conforme as regras de repartição de competências estabelecidas no SUS
}

The Item 793 of the Supreme Court and the compliance for health benefits according to the rules for the division of competences established for Brazilian SUS

Tema 793 de la Corte Suprema y la dirección del cumplimiento de los beneficios de salud de acuerdo con las reglas para la división de competencias establecidas en el SUS de Brasil

Marcia Coli Nogueira ${ }^{1}$

\section{Resumo}

Objetivo: analisar o Tema 793 do STF, que trata da responsabilidade solidária dos entes federados pelo dever de prestar assistência à saúde, e que exigiu do magistrado que direcione o cumprimento da obrigação conforme as regras de repartição de competências. Metodologia: o trabalho utilizou o método dedutivo para compreender os diversos aspectos insertos no voto do relator Ministro Edson Fachin sobre o tema da repartição de competência no SUS, que culminou com a Tese 793 do STF. Resultados: o artigo apresenta as regras básicas de financiamento da assistência farmacêutica; fornece parâmetros para identificar o ente responsável pela prestação da saúde; indica formas de diminuir os custos da judicialização e aponta a União Federal como a maior responsável pelo financiamento da assistência farmacêutica. Conclusão: o Tema 793 não conseguiu ainda trazer uma unicidade das decisões judiciais, e não é claro sobre qual ente federado deva compor o polo passivo e ser condenado nas prestações da saúde. A identificação do devedor da prestação deve ser uma preocupação dos litigantes e dos operadores do direito, inclusive para assunção das eventuais penalidades por descumprimento.

Palavras-chave: Saúde. Financiamento da assistência farmacêutica. Judicialização.

\begin{abstract}
Objective: To overview the Item 793 of the Federal Supreme Court, which deals with the joint liability of federated entities for the duty to provide health care, and which required the magistrate to direct the fulfillment of the obligation according to the rules for the division of competences. Methodology: the the deductive method was applied to understand the various aspects inserted in the vote of the rapporteur Minister Edson Fachin on the subject of the division of competences in the Brazilian public health care system, SUS, which culminated in the Item 793 of the Federal Supreme Court. Results: this paper presents the basic rules for financing pharmaceutical assistance; providing parameters for identifying the provider of health care; it also indicates ways to reduce the costs of judicialization and points to the Federal Union as the main responsible for financing pharmaceutical assistance.
\end{abstract}

\footnotetext{
${ }^{1}$ Procuradora do Estado da Procuradoria-Geral do Estado de São Paulo; integrante da Coordenadoria Judicial de Saúde Pública da PGE (COJUSP); bacharel em Direito da Universidade Presbiteriana Mackenzie; especialista em Direitos Humanos e em Direito do Estado pela Escola Superior da Procuradoria-Geral do Estado de São Paulo. E-mail: marciacoli@globo.com
} 
Conclusion: Item 793 has not yet been able to bring a single court decision, and it is not clear about which federated entity should male part of the factual matter and be condemned in health benefits. The identification of the debtor of the benefit should be a concern of the litigants and the legal operators, including the assumption of possible penalties for noncompliance.

Keywords: Health. Pharmaceutical care financing. Judicialization.

\section{Resumen}

Objetivo: analizar el Tema 793 de la Corte Suprema, que se ocupa de la responsabilidad conjunta y solidaria de las entidades federadas por el deber de brindar atención médica, y que requiere que el magistrado dirija el cumplimiento de la obligación de acuerdo con las reglas para la división de competencias. Metodología: el trabajo utilizó el método deductivo para comprender los diversos aspectos insertados en la votación del relator Ministro Edson Fachin sobre el tema de la división de competencias en el SUS, que culminó con el Tema 793 del STF. Resultados: el artículo presenta las reglas básicas para financiar la asistencia farmacéutica; proporciona parámetros para identificar al proveedor de atención médica; Indica formas de reducir los costos de la judicialización y señala a la Unión Federal como el principal responsable de financiar la asistencia farmacéutica. Conclusión: el Tema 793 aún no ha sido capaz de presentar una decisión judicial única, y no está claro qué entidad federada debería conformar el polo pasivo y ser condenado en beneficios para la salud. La identificación del deudor del beneficio debe ser una preocupación de los litigantes y los operadores legales, incluida la asunción de posibles sanciones por incumplimiento.

Palabras clave: Salud, Financiación de la atención farmacéutica. Judicialización.

\section{Introdução}

O Supremo Tribunal Federal (STF) voltou a tratar das ações que versam sobre a saúde pública ao pautar novamente três Recursos Extraordinários (RE) com repercussão geral, que estavam pendentes de julgamento. São eles: i) RE no 657.718/MG - dever de fornecer medicamento não registrado na Anvisa, Tema 500 (1); ii) embargos de declaração no RE no 855.178/SE - responsabilidade solidária dos entes da Federação, Tema 793 (2); iii) RE no 566.471/RN - dever de fornecer medicamento de alto custo, Tema 6 (3).

Os dois primeiros foram julgados entre os dias 22 e 23 de maio de 2019 , com tese firmada em repercussão geral. O terceiro foi adiado e pautado para o dia 23 de outubro 2019.

Este artigo irá se deter no Tema 793 - Responsabilidade solidária dos entes federados pelo dever de prestar assistência à saúde -, que tem reflexos na legitimidade passiva e está intimamente ligado com as competências administrativas e financeiras estabelecidas e pactuadas dentro do SUS.

A relevância do julgamento do RE no 855.178, que culminou com o Tema 793, é evidente, pois o acerto do polo passivo, sob a ótica da solidariedade, mas também das 
competências administrativas, é condição de procedibilidade. O prosseguimento da demanda, com a condenação equivocada do ente público para prestação do medicamento, terapia ou tecnologia, traz severas consequências ao SUS e a toda coletividade, com a desorganização do sistema.

A solução para os conflitos de competência, com relação ao fornecimento de medicamentos e tratamentos de saúde pela via judicial, perpassa pelo conhecimento das normas do SUS acerca do financiamento da assistência farmacêutica, o que não é tão simples ou evidente.

Há uma dificuldade para a correta identificação do réu na judicialização por tecnologias não incorporadas de "elevado impacto financeiro". Não se tem um conceito e um valor objetivo do que venha a ser "medicamentos que representam elevado impacto financeiro", expressão que permeia a legislação do SUS em diversos momentos.

O trabalho utilizou o método dedutivo para compreender os diversos aspectos insertos no voto do relator Ministro Edson Fachin sobre o tema da repartição de competência no SUS, que culminou com a Tese 793 do STF, e identificou problemas e lacunas que impedem uma judicialização mais racional e menos custosa das prestações da saúde.

\section{Tema 793: responsabilidade solidária dos entes federados pelo dever de prestar assistência à saúde}

O acórdão no RE nำ 855.178, proferido em 5 de março de 2015 pelo Ministro Luiz Fux, tinha exposto o tema da solidariedade dos entes federados desta forma:

RECURSO EXTRAORDINÁRIO. CONSTITUCIONAL E ADMINISTRATIVO. DIREITO À SAÚDE. TRATAMENTO MÉDICO. RESPONSABILIDADE SOLIDÁRIA DOS ENTES FEDERADOS. REPERCUSSÃO GERAL RECONHECIDA. REAFIRMAÇÃO DE JURISPRUDÊNCIA. O tratamento médico adequado aos necessitados se insere no rol dos deveres do Estado, porquanto responsabilidade solidária dos entes federados. O polo passivo pode ser composto por qualquer um deles, isoladamente ou conjuntamente (4)

O referido acórdão foi objeto de embargos de declaração por parte da União Federal, cujo julgamento ocorreu em 22 de maio de 2019, quando o STF definiu a tese sobre a responsabilidade solidária dos entes da federação em matéria de saúde pública, nos seguintes termos: 
TEMA 793: Os entes da federação, em decorrência da competência comum, são solidariamente responsáveis nas demandas prestacionais na área da saúde, e diante dos critérios constitucionais de descentralização e hierarquização, compete à autoridade judicial direcionar o cumprimento conforme as regras de repartição de competências e determinar o ressarcimento a quem suportou o ônus financeiro (2)

\section{O julgamento de maio de 2019 reafirmou a existência da solidariedade entre os entes}

públicos em matéria de saúde, mas inovou ao estabelecer que compete à autoridade judicial direcionar o cumprimento conforme as regras de repartição de competências e determinar o ressarcimento a quem suportou o ônus financeiro (2).

O Ministro Edson Fachin, no voto que culminou com a Tese 793 em estudo, enunciou que:

i) Afirmar que "o polo passivo pode ser composto por qualquer um deles (entes), isoladamente ou conjuntamente" significa que o usuário, nos termos da Constituição (arts. 196 e ss.) e da legislação pertinente (sobretudo a lei orgânica do SUS n. 8.080/90) tem direito a uma prestação solidária, nada obstante cada ente tenha o dever de responder por prestações específicas;

ii) Ainda que as normas de regência (Lei 8.080/90 e alterações, Decreto 7.508/11, e as pactuações realizadas na Comissão Intersetores Tripartite) imputem expressamente a determinado ente a responsabilidade principal (de financiar a aquisição) pela prestação pleiteada, é lícito à parte incluir outro ente no polo passivo, como responsável pela obrigação, para ampliar sua garantia, como decorrência da adoção da tese da solidariedade pelo dever geral de prestar saúde;

iiii) Se o ente legalmente responsável pelo financiamento da obrigação principal não compuser o polo passivo da relação jurídico processual, compete a autoridade judicial direcionar o cumprimento conforme as regras de repartição de competências e determinar o ressarcimento a quem suportou o ônus financeiro, sem prejuízo do redirecionamento em caso de descumprimento;

iv) Se a pretensão veicular pedido de tratamento, procedimento, material ou medicamento não incluído nas políticas públicas (em todas as suas hipóteses), a União necessariamente comporá o polo passivo, considerando que o Ministério da Saúde detém competência para a incorporação, exclusão ou alteração de novos medicamentos, produtos, procedimentos, bem como constituição ou a alteração de protocolo clínico ou de diretriz terapêutica (art. 19-Q, Lei 8.080/90), de modo que recai sobre ela o dever de indicar o motivo da não padronização e eventualmente iniciar o procedimento de análise de inclusão, nos termos da fundamentação (5).

No que pese o esforço do Ministro Fachin de aprimorar e elucidar a tese, não há uma clareza de como proceder com relação à composição do polo passivo em matéria de saúde 
pública, dando azo a diferentes interpretações e decisões judiciais.

Transcreve-se três decisões proferidas por três diferentes Estados após a edição do Tema 793, para exemplificar as disparidades:

Analisando os autos, observo que este juízo necessita adequar seu posicionamento ao recente precedente do STF, cuja observância é obrigatória, conforme dispõe o art. 927, III, do CPC-15.

O Supremo Tribunal Federal, por ocasião do julgamento dos embargos de declaração do Recurso Extraordinário 855178, fixou a seguinte tese (Tema 793):

[...]

A despeito da responsabilidade solidária da União, Estados, Distrito Federal

e Municípios, o precedente impõe que o ente responsável pelo ônus financeiro deve ser trazido ao processo, em litisconsórcio necessário, pois tal medida processual é imprescindível ao direcionamento do cumprimento.

No caso de medicamentos oncológicos, nos termos da decisão do STF, a União deve ser trazida ao processo, porque lhe cabe o custeio do fornecimento de medicamentos para tratamento de câncer.

Medicamentos oncológicos são fornecidos de maneira diferente de fármacos de outras patologias, pois são adquiridos por instituições de saúde habilitadas em oncologia, com base em determinados limites de valor das Autorizações para Procedimento de Alta Complexidade (Apex), para cada tipo de câncer $[\ldots]$

Assim, o medicamento desejado não pode ser adquirido, pois extrapola o teto de valor estabelecido para a patologia da parte autora, o que exige obrigatoriamente a presença da União, a fim de arcar com a ampliação do custo, caso esse valor seja majorado.

Diante do exposto, nos termos do art. 115, parágrafo único, do CPC-151, intime-se a parte autora para, em 15 dias, trazer a União ao polo passivo da demanda (6).

EMENTA: MANDADO DE SEGURANÇA. FORNECIMENTO DE MEDICAMENTO PARA TRATAMENTO DE CÂNCER. ILEGITIMIDADE PASSIVA DO SECRETÁRIO DE SAÚDE DO ESTADO DE GOIÁS. APLICAÇÃO DA TESE FIRMADA NO RE 855.178/SE, JULGADO SOB A SISTEMÁTICA DA REPERCUSSÃO GERAL. I. Nos termos do artigo 6으, § 3ㄴ, da Lei 12.016/09, considera-se autoridade coatora aquela que tenha praticado o ato impugnado ou da qual emane a ordem para a sua prática. II. A omissão relativa à dispensação de medicamento antineoplásico, considerado o esquema de financiamento e repartição de competências do SUS, exsurge imponível ao Gestor Federal. III. Em obediência à tese fixada no RE 855.178/SE, julgado sob a sistemática da repercussão geral, colhe-se irrefragável o reconhecimento da ilegitimidade do Secretário de Saúde do Estado de Goiás, para figurar no polo passivo do mandamus, haja vista não ser esta a autoridade imbuída de competência para corrigir a ilegalidade indicada pela impetrante. IV. A circunstância do deslocamento da competência para processar e julgar o mandamus torna insuscetível de acolhimento o requerimento de emenda da petição inicial. Precedentes do STJ. IV. O reconhecimento da ilegitimidade passiva do impetrado autoriza a 
extinção da ação sem resolução do mérito, com a consequente denegação da segurança. ILEGITIMIDADE PASSIVA RECONHECIDA. SEGURANÇA DENEGADA (7).

O Plenário do STF fixou em sede de repercussão geral, no julgamento do RE $855.178 / \mathrm{SE}$, a seguinte disposição a respeito das responsabilidades dos entes integrantes do SUS:

$[\ldots]$

A entrega de fraldas se trata de responsabilidade própria de saúde básica, daí que o suporte do ônus financeiro deve ser carreado ao ente público municipal, dentro da escala hierárquica de responsabilidade dos entes associados ao SUS.

Diante de tal quadro, o mais adequado é a responsabilização da Municipalidade para a entrega dos bens pleiteados nesta demanda, sem necessidade de inclusão dos demais entes federativos [...].

Ante o exposto, JULGO PROCEDENTE, EM PARTE, a ação promovida por JOSÉ BARRETO GUIMARÃES contra a MUNICIPALIDADE DE SÃO PAULO, a condenar esta a fornecer a esse, a quantidade de 120 fraldas geriátricas mensais [...].

Por outro vértice, JULGO IMPROCEDENTE a mesma demanda promovida contra a FAZENDA PÚBLICA DO ESTADO DE SÃO PAULO, por ilegitimidade de parte em carrear o ônus ora estabelecido em favor do requerente (8).

Há dúvida e muita incerteza de como se deve dar o direcionamento da demanda ao ente responsável pela prestação e o deslocamento da competência. Não se sabe se o juiz deve incluir o réu de ofício, se a parte precisa aditar sob pena de extinção, ou se há ilegitimidade de parte ou litisconsórcio passivo necessário, face à responsabilidade solidária dos entes federados. São questões processuais que precisam ser enfrentadas, mas não será objeto deste estudo.

O trabalho optou por dar concretude ao Tema 793, identificando as repartições de competências dentro do SUS, e apresentar o devedor principal. Para tanto, é necessário entender como se dá o financiamento das ações e serviços dentro da assistência farmacêutica.

\section{O financiamento da assistência farmacêutica}

A assistência farmacêutica é responsável por garantir à população o acesso à medicamentos essenciais, adotando como diretriz a Relação Nacional de Medicamentos Essenciais (Rename), que é o elenco de medicamentos indicados para o atendimento de doenças ou de agravos no âmbito do SUS. 
O bloco de financiamento para a assistência farmacêutica é constituído por três componentes: componente básico da assistência farmacêutica (Cbaf) ${ }^{2}$; componente estratégico da assistência farmacêutica (Cesaf) ${ }^{3}$; e componente especializado da assistência farmacêutica (Ceaf) ${ }^{4}(9)(10)$.

Os medicamentos do Cbaf tratam as doenças mais prevalentes na população, voltados aos programas de saúde da atenção básica e são dispensados pelos Municípios, por meio das unidades básicas de saúde. Os três entes da Federação são os responsáveis pelo financiamento, por meio de repasses com base no número de habitantes, conforme artigo 537 e seguintes da Portaria de Consolidação no 06/2017 (10).

Os medicamentos do Cesaf tratam de epidemias e endemias, tais como tuberculose, hanseníase, malária, leishmaniose, doença de chagas, bem como outras doenças decorrentes e perpetuadoras da pobreza. Também são garantidos antivirais para o combate à influenza, antirretrovirais para tratamento de pessoas vivendo com HIV/Aids, hemoderivados e pró-coagulantes para pessoas com doenças hematológicas, vacinas, soros e imunoglobulinas, além de medicamentos e insumos destinados ao combate do tabagismo e ao programa de alimentação e nutrição, conforme artigo 536 da Portaria de Consolidação no 06/2017 (10). O responsável pelo financiamento é a União, por meio do Ministério da Saúde, que adquire e repassa aos Estados e que, por sua vez, distribuem aos Municípios.

Os medicamentos do Ceaf visam a integralidade do tratamento, cujas linhas de cuidados estão definidas em protocolos clínicos e diretrizes terapêuticas (PCDT), publicados pelo Ministério da Saúde (9) 5 . Os medicamentos que constituem as linhas de cuidado para as doenças contempladas nesse componente estão divididos em três grupos com características, responsabilidades e formas de organização distintas, como consta do anexo XXVIII, artigo 49 da Portaria de Consolidação no 02/2017:

I- Grupo 1: medicamentos sob responsabilidade de financiamento pelo Ministério da Saúde, sendo dividido em:

\footnotetext{
2 Portaria de Consolidação no 02/2017, Anexo XXVIII, art. 33 e 34 e Portaria de Consolidação no 06/2017, art. 537 e ss.

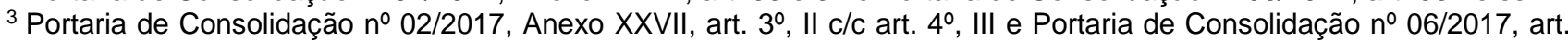
535 , II c/c 536 e ss.

${ }^{4}$ Portaria de Consolidação no 02/2017, Anexo XXVIII, art. 47 e ss. e Portaria de Consolidação nº 06/2017, art. 535, III c/c art. 540 e ss.

${ }^{5}$ Portaria de Consolidação no 02/2017, Anexo XXVIII, art. 47 e 48.
} 
a) Grupo 1A: medicamentos com aquisição centralizada pelo Ministério da Saúde e fornecidos às Secretarias de Saúde dos Estados e Distrito Federal, sendo delas a responsabilidade pela programação, armazenamento, distribuição e dispensação para tratamento das doenças contempladas no âmbito do Componente Especializado da Assistência Farmacêutica; e b) Grupo 1B: medicamentos financiados pelo Ministério da Saúde mediante transferência de recursos financeiros para aquisição pelas Secretarias de Saúde dos Estados e Distrito Federal sendo delas a responsabilidade pela programação, armazenamento, distribuição e dispensação para tratamento das doenças contempladas no âmbito do Componente Especializado da Assistência Farmacêutica;

II - Grupo 2: medicamentos sob responsabilidade das Secretarias de Saúde dos Estados e do Distrito Federal pelo financiamento, aquisição, programação, armazenamento, distribuição e dispensação para tratamento das doenças contempladas no âmbito do Componente Especializado da Assistência Farmacêutica; e

III - Grupo 3: medicamentos sob responsabilidade das Secretarias de Saúde do Distrito Federal e dos Municípios para aquisição, programação, armazenamento, distribuição e dispensação e que está estabelecida em ato normativo específico que regulamenta o Componente Básico da Assistência Farmacêutica (9)

Os grupos definem com clareza os entes públicos responsáveis pelo financiamento: a União Federal financia, diretamente ou por transferência de dinheiro, os medicamentos do Grupo 1, e o Estado financia com exclusividade os medicamentos do Grupo 2. Já o Grupo 3 é constituído por medicamentos cuja responsabilidade pelo financiamento é tripartite, sendo a aquisição e dispensação de responsabilidade dos Municípios $^{6}$ (11).

A Rename, por sua vez, traz a lista de medicamentos fornecidos pelo SUS e os componentes a que pertencem (12). No site da Comissão Nacional de Incorporação de Tecnologias no SUS (Conitec) podem ser consultados os protocolos clínicos e diretrizes terapêuticas (PCDT) (13).

O critério geral para o enquadramento do medicamento do Ceaf em cada um desses três grupos será, dentre outros, o grau de complexidade do tratamento e o valor agregado. Assim, o Grupo 1 é constituído por medicamentos que representam maior impacto financeiro para o Ceaf e por aqueles indicados para doenças mais complexas. Para melhor compreensão, transcreve-se o artigo 50 e 51, do anexo XXVIII da Portaria de Consolidação

\footnotetext{
${ }^{6}$ Essa afirmação consta do site do Ministério da Saúde, no explicativo sobre o Ceaf. Deve-se conjugar o artigo 537 da Portaria de Consolidação no 6/2017, que trata do financiamento do Cbaf, com o artigo 540 da mesma Portaria de Consolidação no 6/2017, que trata do Ceaf, quando deixa claro no seu parágrafo $1^{\circ}$, que "os medicamentos do Grupo 3 são financiados conforme regras de Componente Básico da Assistência Farmacêutica".
} 
nํ 02/2017:

Art. 50. Os grupos de que trata o art. 49 são definidos de acordo com os seguintes critérios gerais:

I - complexidade do tratamento da doença;

II - garantia da integralidade do tratamento da doença no âmbito da linha de cuidado; e

III - manutenção do equilíbrio financeiro entre as esferas de gestão do SUS.

Art. 51. O Grupo 1 é definido de acordo com os seguintes critérios específicos: I - maior complexidade do tratamento da doença;

II - refratariedade ou intolerância a primeira e/ou a segunda linha de tratamento;

III - medicamentos que representam elevado impacto financeiro para o Componente Especializado da Assistência Farmacêutica; e

IV - medicamentos incluídos em ações de desenvolvimento produtivo no complexo industrial da saúde (9)

A União Federal atribuiu para si algumas responsabilidades: i) financiamento, aquisição e/ou distribuição da insulina humana NPH 100 Ul/ml e da insulina humana regular $100 \mathrm{UI} / \mathrm{ml}(9)^{7}$; ii) o Programa Saúde da Mulher: contraceptivos orais e injetáveis, dispositivo intrauterino (DIU) e diafragma, constantes no anexo I e IV da Rename (9)8; iii) a aquisição de medicamento para tratamento de doenças raras proveniente de recursos orçamentários do Ministério da Saúde, conforme estabelece o artigo 44 da Portaria no 199 de 30/01/2014 editada pelo Ministério da Saúde, que institui a Política Nacional de Atenção Integral às Pessoas com Doenças Raras (14); iv) os medicamentos oncológicos: os hospitais oncológicos habilitados na alta complexidade em oncologia no SUS (denominados de Cacon e Unacon) são os responsáveis pelo fornecimento de medicamentos oncológicos e que, livremente, padronizam, adquirem e fornecem. A União, por meio do Ministério da Saúde, realiza o custeio dos procedimentos quimioterápicos da rede pública, na modalidade de reembolso, conforme código da autorização de procedimentos de alta complexidade (Apac), sempre às vistas do procedimento realizado e não da droga utilizada, salvo alguns medicamentos oncológicos que têm aquisição centralizada pelo Ministério da Saúde ${ }^{9}$ (15).

Os medicamentos oncológicos não constam, portanto, dos componentes da assistência farmacêutica. Seria muito razoável supor que pertenceriam ao Grupo 1 do Ceaf,

\footnotetext{
7 Portaria de Consolidação no 02/2017, anexo XXVIII, art. 35 e § único.

8 Portaria de Consolidação no 02/2017, anexo XXVIII, art. 36, incisos I, II.

9 São eles: dasatinibe, mesilato de imatinibe, nilotinibe, rituximabe, trastuzumabe, além da talidomida e zidovudina, cujo acesso é pelo Cesaf (15).
} 
face o grau de complexidade do tratamento da doença e impacto financeiro para 0 componente, o que é mais uma justificativa para serem judicializados contra a União Federal. Ainda que não se faça essa equiparação ou analogia, o critério é bem objetivo, uma vez que o subfinanciamento do ente federal para o custeio das ações da assistência oncológica é determinante para a judicialização, como explica Queiroz, que responsabiliza a União Federal pelo fornecimento de medicamentos oncológicos:

CACONs e UNACONs administram e dispensam medicamentos antineoplásicos, embora tenham as suas ações limitadas pelos valores remuneratórios fixados pela União para as APACs, o que termina por representar uma espécie de "teto de gastos" por paciente oncológico. Na prática, porém, a insuficiência do repasse federal para a assistência oncológica termina por alimentar os números da judicialização[...]. Posto isto, nas hipóteses em que for pleiteado medicamento oncológico não incorporado formalmente, a demanda necessariamente deverá ser deflagrada em face da União (16, grifo da autora).

Em linhas gerais, a União Federal presta atendimentos mais complexos e menos frequentes e, à exceção dos medicamentos constantes do Ceaf do Grupo 2, tem participação em todas as demais situações, haja vista que o financiamento do Cbaf é tripartite. Os Estados prestarão os atendimentos de média complexidade e os Municípios, os mais básicos, de atenção primária, e mais solicitados pela população.

Segundo entendimento de alguns Ministros do STF, a União Federal deve compor necessariamente o polo passivo sempre que a tecnologia pleiteada não constar do SUS, pois a ela foi dada a competência para tratar da incorporação de tecnologia em saúde, atribuição conferida pela Lei no 8.080/90, artigo 19-Q (19). Saliente-se a divergência entre o Ministro Edson Fachin, que aceita a inclusão de outros réus conjuntamente com a União Federal (5) e o Ministro Luís Roberto Barroso, que defende a exclusiva competência da União para fornecer tecnologia não incorporada $(17)^{10}$. Sob a ótica do paciente e do pedido, pode-se ter outra opinião: o autor da demanda tem um objetivo bem mais estreito, tão somente o de receber a medicação ou a tecnologia para si, sem considerações acerca da

\footnotetext{
${ }^{10}$ Cita-se uma sentença do Estado do Maranhão, de 19 de setembro de 2019, que acompanhou o entendimento do Ministro Barroso: "[...] Nesses casos, somente a União tem a possibilidade de decidir pela incorporação ou não de uma nova tecnologia em saúde, por meio da Conitec e do Ministério da Saúde (Lei no 8.080/1990), de forma que o Estado do Maranhão e o Município de São Luís são partes ilegítimas para figurar no polo passivo da presente demanda [...]. Desta forma, acolho a preliminar de ilegitimidade passiva, e revogo a liminar concedida e declino da competência para o processamento e julgamento da presente ação e determino a remessa dos autos para a Justiça Federal - Seção Judiciária do Maranhão" (18).
} 
incorporação da tecnologia em âmbito nacional. Questionar acerca do pedido de incorporação, se existe esse pedido, porque foi negada a incorporação, ou se já ultrapassou o prazo de 180 dias para apreciação, a que faz alusão o artigo 19-R da Lei no 8.080/90 (19), deve ser atribuição de uma ação coletiva a ser respondida pela União Federal, com efeito extrapartes.

A busca pelo responsável pelo cumprimento da obrigação deve ser feita com outros parâmetros, sempre em vista do cenário existente, com a identificação, se possível, de algumas situações, como: i) em qual dos componentes da assistência farmacêutica - Ceab, Cesaf ou Ceaf - consta a medicação; ii) quem é o detentor da política pública; iii) a que doença se refere; iv) qual o nível de atenção, se primário, secundário ou terciário; v) qual o impacto financeiro e complexidade; vi) quem financia a medicação constante dos componentes para o tratamento da doença, que seria a alternativa terapêutica dentro do SUS àquela medicação judicializada. Nessa hipótese, cabe acionar o ente público para fornecer a medicação que poderia estar no SUS, mas não está, e por isso foi judicializada.

No entanto, se a nova tecnologia for de extremo valor agregado e complexidade, a União Federal deverá obrigatoriamente constar do polo passivo, uma vez que cabe a ela o financiamento do Grupo 1A e 1B - nesse último caso, apenas quando houver irregularidade na transferência de recursos -, de acordo com critérios como maior complexidade do tratamento da doença e medicamentos que representam elevado impacto financeiro para o componente especializado da assistência farmacêutica (9) ${ }^{11}$.

Esse caminho foi adotado pelo Presidente do STF, Ministro Dias Toffoli, na Suspensão de Tutela Provisória (STP) no 127 (20), ao conceder liminar, em 20 de maio de 2019, eximindo o Município de Jundiaí (SP) da obrigação de fornecer o medicamento Spinraza $^{\circledR}$ (nusinersen) a paciente com atrofia muscular espinhal (AME), cujas quatro doses da medicação custam mais de $\mathrm{R} \$ 1,1$ milhão. Dois foram os aspectos considerados pelo Ministro para excluir o Município: o altíssimo custo e a complexidade de diagnóstico e tratamento, acompanhado no âmbito do SUS em serviços de referência em doenças raras.

Portanto, a definição de qual réu deva integrar o polo passivo deve levar em conta, além do custo da prestação, a manutenção de uma rede hierarquizada que considere o grau

\footnotetext{
${ }^{11}$ Conforme Portaria de Consolidação no 02/2017, anexo XXVIII, artigo 49, inciso I e artigo 51.
} 
de complexidade do atendimento ao paciente: "Quanto mais complexo o atendimento, mais passível de ser ele afastado do ente local e direcionado a ente mais afeto à especialização técnica: Estados e, sequencialmente, a União (STP № 127)." (20).

Com essa orientação, o Município tende a ser menos demandado, pois não haverá interesse para que componha a lide como garantidor em demandas caras e complexas, a exemplo do pedido de Spinraza ${ }^{\circledR}$. Essa função sempre será da União Federal, e bem menos dos Estados.

Resta agora quantificar o que pode ser considerado como elevado impacto financeiro.

O Ceaf teve origem no antigo componente de medicamentos de dispensação excepcional (CMDE), depois denominado de alto custo, que foi um programa de acesso a medicamentos que não estavam na Rename, por não serem considerados essenciais e cuja dispensação era em caráter excepcional. O valor de um medicamento de alto custo foi quantificado, à época, de forma bem objetiva:

O CMDE surgiu, em 1993, com a denominação de "Programa de Medicamentos Excepcionais", e seu objetivo inicial era o de disponibilizar gratuitamente à população medicamentos de uso ambulatorial, de alto custo, e que não pudessem ser comprados pelos cidadãos. O CMDE continua sendo um programa que visa à cobertura de medicamentos ambulatoriais de alto custo. Não existe consenso sobre a definição de medicamentos de alto custo; uma das propostas diz que medicamentos de alto custo são aqueles cujo valor unitário mensal esteja acima de um salário mínimo, ou medicamentos de uso crônico indicado para doenças muito prevalentes (acima de 1\% da população) cujo custo mensal seja superior a um terço de um salário mínimo (21, grifo da autora).

As juízas federais Ana Carolina Morozowski e Luciana da Veiga Oliveira pensaram no assunto de outra forma: coincidentemente, o valor por elas indicado, com base na tabela CMED (Câmara de Regulação do Mercado de Medicamentos), a partir do qual cabe a União Federal assumir o ônus financeiro, foi de $\mathrm{R} \$ 720,25$, não muito longe do valor do salário mínimo atual, de $\mathrm{R} \$ 954,00$ :

Todavia, tendo em vista que os preços praticados por cada Estado são diferentes, para que se pudesse extrair uma uniformidade em todo o território nacional acerca do limite de custo acima do qual não poderia haver o direcionamento da responsabilidade de financiamento aos Estados e, logicamente, aos Municípios, recorreu-se ao preço da tabela CMED (Câmara de Regulação do Mercado de Medicamentos) dos 12 
medicamentos mais caros elencados na tabela referente ao grupo 2 , sem ICMS pelo PF (preço de fábrica).

Com base nessa pesquisa, aferiu-se que, de fato, pela tabela CMED, o tratamento mais caro imposto ao Estado é o que vem em primeiro lugar na lista, qual seja, a Mesalazina $500 \mathrm{mg}$ comprimido com microgrânulos de liberação prolongada, com o custo mensal médio de $R \$ 720,25$ por paciente. Poder-se-ia concluir, então, que qualquer tratamento que custe mais do que $R \$ 720,25$ por mês, de acordo com a tabela CMED, seria necessariamente de financiamento da União (22, grifo da autora).

A falta de um critério objetivo ou um valor monetário para definir o que seja tecnologia de "elevado impacto financeiro" dificulta uma judicialização correta das tecnologias não incorporadas no SUS. As duas citações acima apontam valor em torno de um salário mínimo como uma prestação de elevado impacto financeiro para justificar a responsabilização da União Federal, em detrimento de Estados e Municípios.

Após a análise das competências administrativas estabelecidas pelo SUS, deve-se entender a responsabilidade solidária em saúde pública como a prestação de serviços de forma conjugada, interligando os serviços de saúde entre os entes federativos, com o partilhamento de responsabilidades sanitárias, e permitindo o referenciamento dos serviços mediante transferências de recursos. A responsabilidade solidária na saúde significa atuar como referência para outros munícipes na execução de ações e serviços, isto é, executar ações e serviços de maior complexidade, recebendo financiamento suficiente dos demais entes. "A solidariedade é regional em essência”, como bem aponta Lenir Santos (23). Essa visão mais larga da solidariedade está de acordo com o objetivo do Tema 793 do STF, que é manter a proteção ao cidadão dentro das regras e normas do SUS.

\section{Efeitos do Tema 793 sobre a judicialização}

O Tema 793 fez expressa previsão do ressarcimento a quem suportou o ônus financeiro. Essa questão já era judicializada, muito embora com decisões divergentes acerca da possibilidade do ressarcimento ${ }^{12}$. Agora a divergência passa a ser de outra ordem: o

\footnotetext{
${ }^{12}$ A título de exemplo: dois acórdãos opostos, o no 0025449-49.2010.8.26.0053 do Tribunal de Justiça de São Paulo (24) e o n 0001029-36.2007.4.02.5113 do Tribunal Regional Federal da $2^{\text {a }}$ Região, um autorizando o regresso e outro negando, respectivamente, sendo que o último apresentou a seguinte finalização da ementa: "[...] 2. O Sistema Único de Saúde SUS - é composto e financiado pela União, Estados-membros, Distrito Federal e Municípios (art. 198, § 1, da CRFB/88), sendo solidária a responsabilidade dos referidos entes no cumprimento dos serviços públicos de saúde prestados à população. 3. Nessa perspectiva, por determinação constitucional tem-se uma conjugação articulada e racional de esforços e iniciativas, razão pela qual tanto a União quanto os Estados, Municípios e o Distrito Federal são diretamente responsáveis pelo financiamento das políticas públicas relativas ao direito à saúde, não havendo, pois, que se falar em direito de regresso,
} 
direito de ressarcimento é certo, mas a dúvida recai sobre a necessidade dos entes implicados no cumprimento e pagamento, de necessariamente comporem a lide. Ante o direito ao contraditório e a ampla defesa, a resposta deve ser positiva, do contrário só restará a ação autônoma, sem que se aproveite o processo em curso. É uma situação que eliminaria a novidade contida do Tema 793, face a existência do artigo 35, inciso VII da Lei 8.080/1990, que já previa o ressarcimento administrativo (19).

Se a permanência de outros réus no polo passivo, como garantia de um eventual inadimplemento do devedor principal, reafirma a solidariedade e protege o cidadão, por outro lado mantém os custos altos e desnecessários, advindos da participação de mais réus do que efetivamente devedores da prestação.

Colocar os três entes no polo passivo não é nada barato e eficiente, nem mesmo para o autor, que deve aguardar a citação e o pronunciamento de todos eles, com infindáveis apartes, idas e vindas, recursos e incertezas. É, sem dúvida, um efeito ruim da solidariedade sob o ponto de vista do Estado, que deve arcar com os custos do processo nas suas diferentes esferas. O Ministro Luís Roberto Barroso, durante o julgamento do Tema 793, advertiu: "a solidariedade não é grátis" (26).

A questão que se apresenta é como diminuir os custos da judicialização advindos da solidariedade sem prejuízo ao paciente, à luz da tese fixada. A resposta está em outro instituto, que passou ao largo da discussão, quando da análise do tema pelo STF. As penalidades e condenação em honorários, que encarecem sobremaneira o processo, devem ser aplicadas somente contra o devedor principal, aquele a quem o juiz direcionou o cumprimento da obrigação e se quedou inerte. Ele, e somente ele, deve ser o responsável pelo pagamento de multas, sequestros, bloqueios judiciais e honorários advocatícios, pois foi quem deu causa à demanda por se omitir ou não cumprir com suas competências administrativas ou com a ordem judicial.

Assim, diminui-se os custos da judicialização, trazendo mais assertividade ao processo judicial, objetividade em relação às penalidades, e menos abuso nas cobranças de multas, dirigidas indistintamente contra todos os entes da Federação. Também se traduz em um incentivo maior ao cumprimento da ordem judicial, ao saber que o ente devedor principal é o único responsável pelo pagamento desses valores.

eis que não se trata daquela solidariedade típica do direito privado" (25). 
Eliminar a duplicidade de penalidades e da sucumbência reduz os custos da judicialização, mas ainda está longe do ideal. A redução ocorreria, é claro, se o sistema de saúde fosse mais eficiente, o que passa pelo planejamento do orçamento dos diferentes entes. Se a questão financeira não é algo tão simples de resolver, outro ponto deveria ser mais bem compreendido, que foi o intuito do Tema 793: a preocupação de identificar quem é o legitimado passivo para as demandas por medicamentos e tratamentos, conforme as regras de repartição de competências.

A despeito da solidariedade que foi garantida ao autor, espera-se uma melhor conscientização e preparação, no sentido de direcionar a demanda para quem tem ou deveria ter a política pública implementada. Claudio Lottenberg (27) pondera que "a conscientização deve partir de médicos, pacientes e de uma judicialização responsável, que não pode ser utilizada por grupos para tirar proveito de situações impróprias". Por outro lado, o SUS melhorou muito a sua comunicação e transparência com a divulgação de toda sorte de informações, facilitando a identificação do ente responsável pela obrigação. A Rename é um importante instrumento de consulta. Traz os medicamentos essenciais do SUS e clareza sobre os responsáveis por garantir a assistência farmacêutica, atendendo muito bem 0 usuário. A Rename é atualizada a cada dois anos, disponibilizada online e traz a informação sobre o medicamento de várias formas, indicando o componente ao qual pertence (12).

Essa é a "judicialização fácil” a que fez menção o Ministro Luís Roberto Barroso (26). Quando o ente, que tem a política pública definida, falha na sua missão, ele deve obrigatoriamente constar do polo passivo e ser instado a cumprir a obrigação pelo juiz. A Rename, juntamente com outros instrumentos de pesquisa e listas estaduais e municipais de medicamentos, como a Relação Municipal de Medicamentos (Remume), orientam a formação do polo passivo, e o juiz deve exigir esse cuidado do litigante ao direcionar seu pedido, com a consequente deslocação da competência se necessário.

A judicialização mais difícil é a que pede medicação ou tecnologia com registro na Anvisa, de alto custo e que não foram incorporados no SUS. O RE no 566.471 que trata deste assunto (Tema 6) (3) tem previsão de julgamento para 23 de outubro de 2019. Essa é uma importante oportunidade para o STF pacificar e orientar os mais de 33.495 processos sobrestados (28) e esclarecer as dúvidas ainda existentes sobre a composição do polo passivo, o deslocamento de competência, o ressarcimento e o que representa medicamento de "elevado impacto financeiro". 


\section{Conclusão}

A correta judicialização da saúde pública deve compatibilizar as regras de financiamento da assistência farmacêutica com a responsabilidade solidária dos entes públicos, que foi reafirmada no julgamento do RE no 855.178 (Tema 793).

A solidariedade tem o intuito de conferir proteção para o cidadão, aquele que está na ponta do sistema e necessita do medicamento ou tratamento. A formulação da Tese 793 não retrocedeu nesta proteção, mas trouxe um alívio ou uma tentativa de organizar melhor a prestação jurisdicional, ao exigir do juiz que direcione o cumprimento da obrigação ao ente competente administrativamente, pois se as competências são desorganizadas e sobrepostas, o sistema anda mal e o atendimento se precariza.

O Supremo Tribunal Federal acertou ao valorizar as diretrizes do SUS, mandando respeitar os critérios de hierarquização e descentralização que dão sustentação ao SUS e evitam a nefasta e cara duplicidade de meios para fins idênticos.

Para o Tema 793 ser concretizado e refletir uma judicialização menos custosa e mais assertiva, o ente responsável pela prestação da saúde deve constar necessariamente na demanda, aceitando-se uma maior abertura na composição do polo passivo para as hipóteses sem clara definição.

Uma linha a mais ao enunciado para direcionar também as multas, penalidades e honorários advocatícios ao ente devedor principal, com exclusividade, traria efeitos benéficos para a judicialização. Em matéria de direito, nada é tão óbvio que não mereça uma atenção.

Passados 30 anos da Constituição da República Federativa do Brasil e da criação do SUS, há uma preocupação traduzida em Tema de repercussão geral, com alcance erga omnes, com a sobreposição de ações e a estrutura do SUS, compreendido como sendo um sistema integrado, organizado em uma rede de atendimento regionalizada e hierarquizada, conforme níveis de complexidade dos serviços, como bem explica o artigo 198 da Constituição Federal.

\section{Referências}

1. Brasil. Supremo Tribunal Federal. Recurso Extraordinário 657.718-MG. Recorrente: Alcirene de Oliveira. Recorrido: Estado de Minas Gerais. Relator: Ministro Marco Aurélio Mello. Brasília, 22.mai.2019. Disponível em: http://portal.stf.jus.br/processos/detalhe.asp? 
incidente $=4143144$ [Acesso em 02. ago. 2019].

2. Brasil. Supremo Tribunal Federal. Recurso Extraordinário 855.178-SE. Recorrente: União Federal. Recorrido: Maria Augusta da Cruz Santos. Relator: Ministro Luiz Fux. Brasília, 22.mai.2019. Disponível em: http://portal.stf.jus.br/processos/detalhe.asp?incidente=4678356 [Acesso em 02. ago. 2019].

3. Brasil. Supremo Tribunal Federal. Recurso Extraordinário 566471-RN. Recorrente: Estado do Rio Grande do Norte. Recorrido: Carmelita Anunciada de Souza. Relator: Ministro Marco Aurélio. Brasília, 28.09.2016. Disponível em: http://www.stf.jus.br/portal/processo/verProcesso Detalhe. asp? incidente=2565078 [Acesso em 02. ago. 2019].

4. Brasil. Supremo Tribunal Federal. Disponível em: http://portal.stf.jus.br/processos/ downloadPeca. .asp?id=15319097113\&ext=.pdf [Acesso em 02.ago.2019].

5. Brasil. Supremo Tribunal Federal. Disponível em: http://www.stf.jus.br/arquivo/cms/Biblioteca ConsultaProdutoBibliotecaPastaFachin/anexo/RE855178ED.pdf.fls.43/44 [Acesso em 20.jul.2019].

6. Paraíba. $5^{\mathrm{a}}$ Vara da Fazenda Pública. Processo oํ 0852844-47.2019.8.15.2001. Autor: Suely Cristina Silva de Oliveira Albuquerque. Requerido: Estado da Paraíba. João Pessoa, 19.set.2019.

7. Brasil. Tribunal de Justiça do Estado de Goiás. Mandado de Segurança no 5493365.68.2019.8.09.0000. Impetrante: Maria Teles Ferreira. Impetrado: Secretário de Saúde de Goiás. Relator: Maurício Porfírio Rosa, Goiás, 28.ago.2019.

8. São Paulo. 2 ${ }^{\underline{a}}$ Vara do Juizado Especial da Fazenda Pública. Processo oㅜ 106482544.2018.8.26.0053. Autor: José Barreto Guimarães. Réu: Municipalidade de São Paulo. São Paulo, 27.mai.2019.

9. Brasil. Ministério da Saúde. Portaria de Consolidação no 02, de 28 de setembro de 2017. Dispõe sobre a Consolidação das normas sobre as políticas nacionais de saúde do Sistema Único de Saúde. Disponível em: http://bvsms.saude.gov.br/bvs/saudelegis/gm/2017/ prc0002_03_10_2017.html [Acesso em 23.jul.2019].

10. Brasil. Ministério da Saúde. Portaria de Consolidação no 06, de 28 de setembro de 2017. Dispõe sobre Consolidação das normas sobre o financiamento e a transferência dos recursos federais para as ações e os serviços de saúde do Sistema Único de Saúde. Disponível em: http://bvsms.saude.gov.br/bvs/saudelegis/gm/2017/ prc0006_03_10_2017.html\#TITULOVC APIISECI [Acesso em 23.jul.2019].

11. Brasil. Ministério da Saúde. Disponível em: http://www.saude.gov.br/assistenciafarmaceutica/medicamentos-rename/componente-especializado-da-assistenciafarmaceutica-ceaf [Acesso em 20.7.2019]. 
12. Brasil. Ministério da Saúde. RENAME. Disponível em: http://conitec.gov.br/images/Artigos_Publicacoes/Rename/Rename_2018_Novembro.pdf [Acesso em 23.jul.2019].

13. Brasil. Ministério da Saúde. CONITEC. Disponível em: http://conitec.gov.br/index.php/protocolos-e-diretrizes [Acesso em 23.jul.2019].

14. Brasil. Ministério da Saúde. Portaria no 199 de 30/01/2014. Institui a Política Nacional de Atenção Integral às Pessoas com Doenças Raras. Disponível em: http://bvsms.saude.gov.br/bvs/saudelegis/gm/2014/prt0199_30_01_2014.html [Acesso em 25.jul.2019].

15. Brasil. Ministério da Saúde. Disponível em: http://www.saude.sp.gov.br/ses/perfil/gestor/ assistencia-farmaceutica/medicamentos-oncologicos [Acesso em 20.7.2019].

16. Queiroz RLG. Nota técnica № 003/2019. Ministério Público do Estado da Bahia.

17. Pompeu A. Responsabilidade por fornecimento de remédios é solidária, reafirma Supremo. Disponível em: https://www.conjur.com.br/2019-mai-22/responsabilidadefornecimento-remedios-solidaria-stf [Acesso em 20.jul.2019].

18. Maranhão. 6a Vara da Fazenda Pública de São Luís. Processo no 0835440 07.2019.8.10.0001. Autor: Ana Rosa Rocha Gomes Silva. Réu: Estado do Maranhão e Município de São Luís. São Luís, 19.set.2019.

19. Brasil. Lei no 8.080 de 19 de setembro de 1990. Dispõe sobre as condições para a promoção, proteção e recuperação da saúde, a organização e o funcionamento dos serviços correspondentes e dá outras providências. Disponível em: http://www.planalto.gov.br/ ccivil_03/leis/l8080.htm [Acesso em 24.jul.2019].

20. Brasil. Supremo Tribunal Federal. Suspensão de Tutela Provisória 127-SP. Requerente: Município de Jundiaí. Requerido: TRF-3a Região. Ministro Dias Toffoli. Brasília, 16.mai.2019.Disponível em: http://portal.stf.jus.br/processos/downloadPeca.asp?id= 15340214438\&ext=.pdf [Acesso em 15.jul.2019].

21. Souza MV, Krug BC, Picon PD, Schwart IVD. Medicamentos de alto custo para doenças raras no Brasil: o exemplo das doenças lisossômicas. Disponível em: https://www.scielosp.org/article/csc/2010.v15suppl3/3443-3454/pt/ [Acesso em 15.jul.2019].

22. Morozowski AC, Oliveira LV. Da responsabilidade solidária na assistência à saúde no SUS. Disponível em: https://www.migalhas.com.br/dePeso/16,MI305311,91041:Da+ responsabilidade+solidaria+na+assistencia+a+saude+no+SUS [Acesso em 15.jul.2019].

23. Santos L. Judicialização da Saúde e a incompreensão do SUS. In: Santos L, Terraza F (org.). Judicialização da saúde no Brasil. São Paulo: Saberes Editora; 2014. 
24. Brasil. Tribunal de Justiça de São Paulo. Apelação cível no 0025449-49.2010.8.26.0053. Apelante: Fazenda do Estado de São Paulo. Apelado: Município de Barueri da Comarca de São Paulo. Relator Ronaldo Frigini. São Paulo, 2.jun.2014. Disponível em: https://esaj.tjsp.jus.br/cposg/show.do?processo.foro=990\&processo.codigo=RI0023FDZ000 0. [Acesso em 21.jul.2019].

25. Brasil. Tribunal Regional Federal da 2a Região. Apelação cível no 0001029 36.2007.4.02.5113. Apelante: União Federal. Apelado: Município de Três Rios. Relator: José Antonio Neiva. Rio de Janeiro, 12.set. 2012.

26. Youtube. 22.5.2019. 11min32s. Pleno - Responsabilidade solidária de entes federados na assistência à saúde. Disponível em: https://www.youtube.com/watch?v=UgIMjsAHqIM. 22.5.2019 [Acesso em 21.jul.2019].

27. Lottenberg C. Seminários Folha - A saúde do Brasil. Folha de São Paulo. Caderno especial, 22.mai.2019.

28. Hyndara F. 42 mil processos aguardam decisão do STF sobre judicialização da saúde. Disponível em: https://www.jota.info/stt/do-supremo/42-mil-processos-aguardam-decisaodo-stf-sobre-judicializacao-da-saude-21052019 [Acesso em 21.mai.2019].

Como citar este artigo:

Nogueira MC. O Tema 793 do STF e o direcionamento do cumprimento das prestações na área de saúde conforme as regras de repartição de competências estabelecidas no SUS. Cadernos Ibero-Americanos de Direito Sanitário. 2019 out./dez.; 8(4): 08-26.

http://dx.doi.org/10.17566/ciads.v8i4.558 